\title{
HOW LONG CAN THE PREVIOUSLY ASSEMBLED CARDIOPULMONARY BYPASS CIRCUIT STAY STERILE?
}

\author{
Vladimír Lonský, Barbora Voxová*, Jan Dominik, Jiří Mand’ák, Jaroslav Kubíček, Jaroslava Bímová, \\ Dana Marková, Pavla Matoulková \\ Department of Cardiac Surgery, Charles University, Faculty of Medicine and Teaching Hospital, Hradec Králové; \\ (Head: doc. MUDr. J. Dominik, CSc.) \\ Department of Clinical Microbiology, Charles University, Faculty of Medicine, Hradec Králové; \\ (Head: doc. MUDr. J. Horáček, CSc.)*
}

\begin{abstract}
Summary: The sterility of previously assembled cardiopulmonary bypass circuits was investigated for 100 extracorporeal circuits. The closed circuits were assembled using aseptic technique and remained in the pump room until time of use. The mean time from point of setup to point of priming for the 100 consecutive circuits was 32 hours, with a range of 19 to 89 hours. Circuits were primed with the calculated volume of priming solution, circulated for 5 minutes and tested for microbial contamination by withdrawing $20 \mathrm{ml}$ of the priming solution and 10 days incubated in Thioglycolate and Sabouraud culture mediums. All were found to be free of microbial comtamination. The results of this investigation demonstrate that the sterility of the extracorporeal circuit, pre-assembled in advance of actual priming, can be maintained over an extended interval when standard aseptic technique is used. This allows the utilization of a pre-assembled circuit for emergency cardiopulmonary support.
\end{abstract}

Key words: Open heart surgery; Cardiopulmonary bypass; Cardiopulmonary bypass circuit; Microbial contamination; Pre-assembling of circuit

\section{Introduction}

The initiation of immediate cardiopulmonary bypass in emergency situations is life-saving. However, before emergency cardiopulmonary bypass can begin, the perfusionist must aseptically assemble, prime and debbuble the extracorporeal circuit as quickly as possible. The availability of previously assembled, sterile extracorporeal circuit in these instances can save 20-40 critical minutes.

Although a number of investigations $(3,6,8)$ of the causes of infection in open heart surgery patients have considered cardiopulmonary bypass apparatus, we have found only two reports examining the sterility of assembled extracorporeal circuits. The first one is from 1990. Chorak (2) examined 26 circuits preassembled 24-96 hours prior to priming. He tested the sterility with Bactec NR 660 nonradiometric system and he found all circuits to be sterile. The second one is from 1993. Homishak (5) tested 17 circuits preassembled 13-60 hours with Addi-Chek Quality Control System. He also found all of them to be free of microbial contamination. Because of a such poor information about so important topic, which sterility of extracorporeal circuits certainly is, we have decided to perform our own investigation using larger ammount of tested circuits.

\section{Material and methods}

We have investigated one hundred consecutive previously assembled cardiopulmonary bypass circuits.

Our extracorporeal circuits tested consisted of POLYSTAN'S SAFE I closed system (POLYSTAN A/S, Vaerlose, Denmark). A large portion of the circuit was preassembled in a Polystan\#s custompack with 7 connections required to complete the set-up.

The extracorporeal setups were assembled and the remaining 7 connections made aseptically with all vents, accesory lines and priming ports remaining capped. The heart-lung machine was covered with a clean sheet and remained in the pump room which is situated between our two operating rooms until next surgery case. At the time of the surgery, the vent caps were removed and remaining connections were completed, the heater-cooler was connected to the oxygenator heat exchanger and circulated. The circuit was then primed with adequate volume of our antibiotic free priming (Tab.1) with recirculation through both reservoirs, the arterial filter, and the oxygenator at a flow of two liters per minute for 5 minutes and system was debbubled.

After recirculation $20 \mathrm{ml}$ of priming was taken into the sterile test-tube for microbiological testing. For our sterility 
tests we have chosen the bacteriological methods which are described in detail in the summary of pharmaceutical tests (7), which are used in our country as a quality control system for pharmacists to determine the microbial quality of intravenous solutions. The samples were injected into culture mediums and were incubated for ten days. As the culture mediums to monitor microbial growth there were used Thioglycolate medium for aerobes and anaerobes detection and Sabouraud medium for fungi detection. For a sample to be considered positive the culture mediums must have appeared turbid at some point during the 10 day incubation interval.

Table 1: Oxygenerator prime

\begin{tabular}{|l|l|}
\hline Hartmann's solution & $750-1000 \mathrm{ml}$ (acc. weight) \\
\hline Rheomacrodex & $3 \% 500 \mathrm{ml}$ \\
\hline Mannitol & $10 \% 1,0 \mathrm{~g} / \mathrm{kg}$ \\
\hline Natrium bicarbonate & $8,4 \% 1 \mathrm{mmol} / \mathrm{kg}$ \\
\hline Magnesium sulphuricum & $20 \% 10 \mathrm{ml}$ \\
\hline Heparin & $2500 \mathrm{U}$ \\
\hline Metylprednisolon & $5 \mathrm{mg} / \mathrm{kg}$ \\
\hline Ascorbic acid & $1000 \mathrm{mg}$ \\
\hline
\end{tabular}

\section{Results}

One hundred extracorporeal circuit set-ups were tested for microbial contamination using the above mentioned microbiological methods. Time elapsed from set-up of the circuit to priming ranged from 19 to 89 hours with a mean time of 32 hours (Tab. 2 and Fig. 1). Most of the circuits - 75 - were preassembled twenty to twenty nine hours which is approximately from one day in advance.

All the 100 tested circuits were found to be sterile. No turbidity in the culture mediums was found.

Table 2: Times from setup to priming (hours)

\begin{tabular}{|c|c|c|c|c|c|c|c|c|}
\hline $\begin{array}{c}\text { TIME } \\
\text { (hours) }\end{array}$ & $10-19$ & $20-29$ & $30-39$ & $40-49$ & $50-59$ & $60-69$ & $70-79$ & $80-89$ \\
\hline $\begin{array}{c}\text { NUMBER } \\
\text { OF CIRCUITS }\end{array}$ & 3 & 75 & 1 & 3 & 1 & 7 & 7 & 3 \\
\hline
\end{tabular}

Fig. 1: Times from setup to priming (hours)

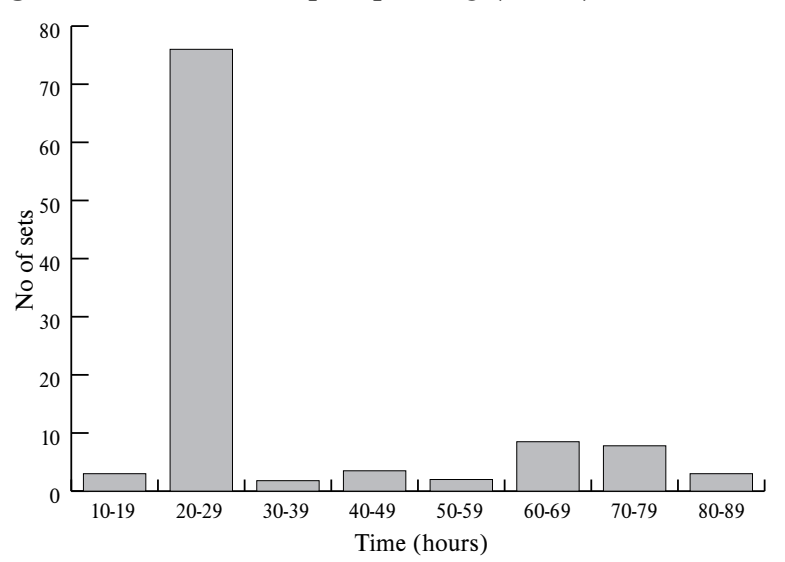

\section{Discussion}

Mediastinal, intracardiac and wound infections are still very serious complications of open - heart surgery. In spite of widespread use of prophylactic antibiotics, the incidence of these infections is still within the range of $2 \%$ in most reported series. Several sources of infection have been suggested.

Staphyloccocus aureus and epidermidis are referred as the most common causes of infection. They are present in the microflora of the human skin and through the process of shedding can these microorganisms be spread into the air of operating theaters. Blakemore, Lathrop (1) and their co-workers suggested that aspiration of such a contaminated air into the extracorporeal circuit can cause postoperative infection. However, contamination of the extracorporeal circuit may also be caused by suction of aircontaminated blood from the wound site (8). Another important source of contamination can be the central venous catheter.

The purpose of our investigation was to determine whether an extracorporeal circuit could be aseptically assembled prior to use and sterility maintained over an extended interval without contamination. The possibility to pre-assemble an extracorporeal circuit in advance of emergency cardiac surgery, such as might occur during evenings, nights, weekends, but also just after the routine procedure due to extended postoperative myocardial ischaemia, affords the opportunity for the perfusionists to start the emergent cardiopulmonary bypass without loosing the time. Our results support the very poor knowledge of this problem $(2,5)$ that the pre-assembled extracorporeal circuit can stay sterile without the risk of contamination more than two days.

It is also necessary to keep in mind that all principles of sterile handling with tubing connections have to be adhered. The pump room must be the integrated part of the operating theatres space and operating theatres airconditioning system.

The perfusionist has to make sure that all vent caps are in their positions before connecting the remaining lines in the time of use the circuit, otherwise the circuit cannot be used.

\section{Conclusion}

The results of our study demonstrate the extracorporeal circuit can be assembled for approximately 2,5-3 days prior of cardiac surgery with no risk of contamination when standard aseptic technique is used. This allows to perfusionists the utilization of a preassembled circuit for emergency cardiac surgery which might occur during evenings, nights and weekends without loosing the time.

This project is supported by grant No. 4103-3 of IGA Czech Ministry of Health. 


\section{References}

1. Blakemore WS, McGarrity GJ, Thurer RJ, et al. Infection by air-borne bacteria with cardiopulmonary bypass. Surgery 1971;70:830.

2. Chorak J, Leader I, Patterson M, Kumar A. Sterility of assembled heart-lung pump beyond 48 hours. Am J Infect Control 1990;18:328-30.

3. Freeman R, Hjersing N. Bacterial culture of perfusion blood after open-heart surgery. Thorax1980;35:754-8.

4. Gee LW, Harvey JMGH, Olson WP, Lee ML. Sterility tests systems for product recovery. J Pharm Sci 1985;74:29-32.

5. Homishak RN, Widmer S, Klementowich $M$, Cunningham J, Oblack D. Sterility of previously assembled cardiopulmonary bypass circuits. J Extra-Corp Tech 1993;25:84-6.

6. Kluge RM, Calia FM, McLaughlin JS, Hornick RB. Sources of contamination in open heart surgery. JAMA 1974;230:1445-8.
7. Kolektiv autorů. 4.8. Zkoušení mikrobiologické. In: Kol. autorů: Československý lékopis. Praha:Avicenum, 1987: 115-7.

8. VanOevern W, Dankert J, Boonstra PW, Elstrod JM, Wildevuur CR. Airborne contamination during cardiopulmonary bypass: the role of cardiotomy suction. Ann Thorac Surg 1986;41:401-6.

Submitted January 1998.

Accepted May 1998.

MUDr. Vladimír Lonský, Department of Cardiac Surgery, Charles University, Faculty of Medicine and Teaching Hospital, 50005 Hradec Králové, Czech Republic. 